\title{
Evaluación de la transmisión y capacidad de infección por contacto directo desde cerdos inoculados experimentalmente con el aislado chileno del virus síndrome respiratorio y reproductivo porcino ${ }^{\#}$
}

\author{
Evaluation of the transmission and infectious capacity by direct contact \\ with pigs experimentally inoculated with the Chilean isolate of the porcine \\ reproductive and respiratory syndrome virus
}

\author{
E Ramírez ${ }^{1,2}$, M Quintana ${ }^{1}$, A Ruiz ${ }^{1}$, A Islas ${ }^{1}$, C Lecocq ${ }^{3}$, L Cerda ${ }^{3}$, M Quezada ${ }^{1 *}$ \\ ${ }^{1}$ Facultad de Medicina Veterinaria, Universidad de Concepción, Avda. Vicente Méndez 595, Chillán (Chile). \\ ${ }^{2}$ Programa de Doctorado en Ciencias Agropecuarias, Mención Patología Animal, Avda. Vicente Méndez 595, Chillán (Chile). \\ ${ }^{3}$ Departamento de Laboratorios y Estaciones Cuarentenarias Agrícolas y Pecuarias, Complejo Lo Aguirre, \\ Servicio Agrícola y Ganadero, Avda. Bulnes 140 (Chile).
}

\begin{abstract}
SUMMARY
The objective of this study was to determine the infectiousness and transmission capacity of the Chilean isolate of the PRRS virus to swine susceptible via direct contact. Therefore, 30 pigs, divided into 6 groups of 5 animals each, were used, one of which (G1) was inoculated with the virus and maintained in isolation unit 1 for 35 days, during which period blood samples were taken at $0,3,7,11,15,19,23,27,31$ and 35 days post infection (dpi) for haemogram and viral isolation. Another group (G6) was used as a control and maintained in isolation unit 3. The remaining groups (G2, G3, G4, G5) were exposed by direct contact to the animals of G1 between 3 to 7, 10 to 14, 17 to 21 , and 24 to 28 dpi, respectively, and later were taken to isolation unit 2 for 7 days. These animals were sampled for the viral isolate and haemograms at 0,5 and 12 days post contact (dpc). At slaughter of G1 and G6 (35 dpi) and the contact groups (12 dpc) samples were collected from nasal mucous, tonsils, submandibular lymph node, lung and spleen for histopathological and immunohistochemical (IHC) study and samples of the tonsils and lungs for viral isolation. Only the pigs of G1 had a transitory fever and neither respiratory symptoms nor alterations in the haematological parameters were registered in the pigs of all groups. At necropsy, lymphadenopathy was observed in all the groups. Histopathologically, all the pigs of G1 had interstitial pneumonia, although via IHC few immunostained cells were detected. In lymphatic tissues, hyperplasia and lymphatic necrosis were observed. In all the pigs, cells positive to IHC were detected, especially in G3 and G4. The virus was isolated from blood between 3 and 23 dpi in G1, and between 5 and 12 dpc in G2 and G3; however it was not isolated from the serum of G4 and G5. The virus was isolated from the tonsils of all the pigs of G1 and the contact groups, although it was not isolated from the lungs in G4. These results indicate that the inoculated pigs are capable of transmitting the disease to susceptible pigs, including in the absence of viremia during a period of 28 days.
\end{abstract}

Palabras clave: síndrome respiratorio y reproductivo porcino, transmisión, infección.

Key words: porcine reproductive and respiratory syndrome virus, transmission, infection.

\section{INTRODUCCION}

El Síndrome Respiratorio y Reproductivo Porcino (PRRS) es una de las enfermedades del cerdo que ha causado gran impacto económico en la industria porcina mundial los últimos 20 años. La enfermedad es causada por un virus ARN envuelto perteneciente a la familia Arteriviridae (Cavanagh 1997) que causa severos cuadros reproductivos, caracterizados por abortos tardíos y enfermedad respiratoria especialmente en cerdos jóvenes (Benfield y col 1992). La enfermedad fue descrita por primera vez en 1987 en Estados Unidos y se disemi-

Aceptado: 05.12.2006.

\# Financiado por el Proyecto Fondecyt N ${ }^{\circ} 1040414$.

Manuel Quezada Orellana. $N^{\circ}$ fax: 042-273201. Correo electrónico: mquezad@udec.cl. Casilla de correo: 537 (Chillán). nó rápidamente por todo el mundo. El primer aislamiento se realizó en cultivos de macrófagos alveolares pulmonares (MAPs) en Holanda (Wensvoort y col 1991), y posteriormente fue aislado en diversos países en líneas celulares CL2621 (Collins y col 1992) o MARC 145 (Kim y col 1993). Actualmente existe una gran variedad de aislados del virus PRRS (VPRRS) en el mundo y se ha demostrado que existen diferencias en su patogenicidad, manifestación clínica (Halbur y col $1996^{b}$ ), características antigénicas (Nelson y col 1993, Halbur y col $1996^{\mathrm{a}}$ ) y genéticas (Chung y col 2002, Murtaugh y col 1998).

El virus presenta una serie de complejas características, como la capacidad de mutar (Murtaugh y col 1998), recombinar (Faaberg y col 1999), deprimir el sistema inmunológico (Drew 2000) y de causar enfermedad persistente (Wills y col 1997ª); sin embargo, aún 
existen varios aspectos desconocidos sobre su patogenia, inmunidad y formas de diseminación, por lo cual continúa siendo una de las enfermedades porcinas a la cual se destinan importantes fondos para investigación con el fin de determinar las formas de propagación de los diferentes aislados. La transmisión se produce fundamentalmente por contacto estrecho entre cerdos a través de secreciones respiratorias (Wills y col $1997^{\mathrm{b}}$, $1997^{\mathrm{c}}$, Rossow y col 1994), saliva (Wills y col 1997), orina (Wills y col $1997^{\mathrm{c}}$, Rossow y col 1994), heces (Yoon y col 1993, Rossow y col 1994) y semen (Swenson y col 1994, Christopher-Hennings y col 1995); sin embargo, existen varias vías indirectas a través de las cuales el virus puede diseminarse a la población susceptible, entre las que se incluyen los fomites (Otake y col 2002, $2002^{\mathrm{b}}$ ), artrópodos (Otake y col $\left.2002^{c}, 2003\right)$ y en menor grado a través de aerosoles (Otake y col 2002 ${ }^{\mathrm{d}}$ ). Una vez en el cerdo, el VPRRS se distribuye preferentemente a través de los macrófagos de diferentes tejidos, especialmente en los MAPs (Rossow y col 1996, Halbur y col 1996ª). En cerdos en crecimiento, el VPRRS causa una neumonía intersticial manifestada clínicamente por distrés respiratorio, somnolencia, letargia y ocasionalmente fiebre (Rossow y col 1995, Halbur y col $1996^{\text {b }}$ ).

Las primeras evidencias de la enfermedad en Chile se detectaron a fines del año 1999 a través de un monitoreo de vigilancia realizado por el Servicio Agrícola y Ganadero (SAG), del Estado de Chile. Rápidamente se caracterizó la situación epidemiológica del país, se determinó a través de análisis virológicos que el virus correspondía a un serotipo norteamericano y se realizó un programa de control y erradicación en conjunto entre el SAG, la Asociación de Productores de Cerdos de Chile (ASPROCER) y la empresa privada (Ruiz y col 2003, Pinilla y col 2006). La enfermedad fue reproducida experimentalmente a través de inoculaciones de cerdos con el aislado chileno. Los resultados patológicos (Ramírez y col 2006) y de distribución antigénica (Quezada y col 2005) indicaron que el virus se distribuye de forma multisistémica; sin embargo, la intensidad leve e inconstante de las lesiones sugiere que este aislado sería de baja patogenicidad en condiciones experimentales (Ramírez y col 2006).

En Chile y en varias regiones del mundo ha sido ampliamente utilizada la estrategia de aclimatización de chanchillas como primer paso en el control y estabilización de un plantel infectado. Este procedimiento ha sido realizado a través de la exposición por contacto directo con el serotipo presente en el plantel a través de cerdos infectados postdestete (Dee 1997). La elección de los animales para este proceso es crítico para un adecuado programa de aclimatización. Algunos estudios han revelado que no existe una asociación significativa entre los signos clínicos y la viremia en cerdos de 4 a 6 semanas de edad infectados naturalmente, para escoger adecua- damente los animales a utilizar en un programa de aclimatización (Cuartero y col 2002). Las fallas en este proceso traen como consecuencia el ingreso de animales susceptibles, generando subpoblaciones que aumentan el riesgo de producir un brote clínico de la enfermedad, desestabilizar un plantel bajo control o perpetuar la infección en los reproductores (Dee 1997). Este fenómeno se torna aún más complejo cuando la prevalencia de la enfermedad es menor y la circulación viral disminuye o es de menor duración, siendo más difícil detectar lechones virémicos.

El objetivo de esta investigación fue determinar la capacidad de transmisión e infección del VPRRS desde cerdos inoculados experimentalmente con el aislado chileno a grupos de cerdos susceptibles expuestos por contacto directo, para determinar en qué momentos los cerdos infectados son capaces de transmitir la enfermedad a cerdos susceptibles.

\section{MATERIAL Y METODOS}

Sitio de experimentación y medidas de bioseguridad. La experiencia se realizó en el Departamento de Laboratorios y Estaciones Cuarentenarias Agrícolas y Pecuarias, Complejo Lo Aguirre perteneciente al SAG, el cual dispone de una Unidad de Control de Productos Biológicos constituida por tres dependencias totalmente aisladas una de la otra (unidad experimental 1, 2 y 3), cada una de las cuales cuenta con ducha esclusa independiente de ingreso y salida. Una de las unidades (unidad 2) se encuentra subdividida en dos salas (2A y 2B) totalmente aisladas una de la otra, aunque con una vía de ingreso y salida común.

Cada unidad experimental tiene corrales de 1,8 x 1,3 metros, adaptados para cerdos con piso elevado de concreto parcialmente cubierto con piso plástico ranurado, bebederos automáticos, ventilación mecánica, temperatura controlada y equipados con filtros de aire hepa. Cada una de ellas fue desinfectada (Ortofenilfenol LY-7 al 2\%, Productos Químicos Beryl Ltda.) y fumigada (Ciperkill@, Anasac) antes del inicio de la experiencia para evitar la presencia de moscas y mosquitos.

Para prevenir la transmisión del virus a través del personal, cada dependencia fue manejada como una unidad epidemiológica independiente con personal encargado exclusivamente del manejo y alimentación de los cerdos en cada una de ellas. Previo al ingreso a las unidades el personal debía ducharse y equiparse con buzos, guantes, mascarillas, cofias desechables y botas limpias $\mathrm{y}$, al momento del ingreso a las salas, tenían que pasar a través de un pediluvio.

Durante el período experimental todos los cerdos se mantuvieron con alimento sin antibióticos y el ingreso de éste a cada unidad se realizó de forma independiente, siendo administrado a los animales dos veces al día. 
Virus. Se utilizó el aislado chileno del VPRRS (cepa 2402), serotipo norteamericano, obtenido de planteles nacionales durante el año 2000 por el SAG, aislado y proporcionado por el Dr. Fernando Osorio de la Universidad de Nebraska-Lincoln (Consultor Internacional del Proyecto de Erradicación de PRRS en Chile). El virus se mantuvo en cultivos celulares de línea MARC 145, sometido a dos pasajes y a una concentración de $10^{5,7}$ $\mathrm{TCID}_{50}$.

Animales de experimentación y diseño experimental. Se utilizaron 30 cerdos híbridos, machos, los cuales fueron obtenidos de un plantel monitoreado periódicamente para PRRS y reconocido como libre de la enfermedad por el SAG. Los cerdos fueron divididos al azar en 6 grupos de 5 animales cada uno, los cuales se identificaron individualmente a través de un autocrotal numerado al momento del ingreso a las instalaciones. Previo al inicio del experimento, se obtuvieron muestras de sangre de todos los cerdos para constatar su condición de negativos a VPRRS a través de ELISA (HerdChek PRRS 2XR, IDEXX) RTnPCR (amplificando el ORF7 del genoma viral).

El diseño de la experiencia y distribución por grupos fue el siguiente:

Grupo 1 (G1): los cerdos de este grupo $(n=5)$ ingresaron a la unidad 1 con 3 semanas de edad y fueron sometidos a una semana de aclimatización. Posteriormente, fueron inoculados con $2 \mathrm{~mL}\left(10^{5,7} \mathrm{TCID}_{50} / \mathrm{mL}\right)$ del VPRRS por vía intranasal y $1 \mathrm{~mL}$ por vía intramuscular. Este grupo permaneció por 35 días en la unidad 1. La temperatura corporal y los síntomas clínicos fueron monitoreados y registrados diariamente.

Grupos contacto (G2, G3, G4 y G5): cada grupo estuvo constituido por 5 cerdos de 4 semanas de edad. Los cerdos de G2, G3, G4 y G5 fueron ingresando directamente a la unidad 1 , donde fueron puestos en contacto directo por 5 días con los animales de G1 entre los 3 y 7 , 10 y 14, 17 y 21, y 24 y 28 días postinoculación (dpi), respectivamente (figura 1), dejando un período de 2 días donde los cerdos de G1 permanecieron sin animales contacto. Luego de este período de contacto los cerdos de cada grupo fueron trasladados a una de las salas de la unidad 2 (sala 2A o 2B según correspondiera), donde permanecieron por 7 días previo al sacrificio. Posteriormente se realizó un lavado y desinfección (Ortofenilfenol LY-7 al 2\%) de las salas de la unidad 2 entre la salida y la llegada de cada uno de los grupos contacto, dando un vacío sanitario de 1 semana a una de ellas mientras la otra era utilizada.

Grupo 6 (G6): los cerdos de este grupo fueron inoculados con $2 \mathrm{~mL}$ intranasal y $1 \mathrm{~mL}$ intramuscular de un cultivo celular MARC 145 no infectado con el VPRRS. En ellos se realizaron, paralelamente, las mismas observaciones y análisis que al grupo inoculado (G1). Estos animales permanecieron por 35 días en la unidad 3 .
Toma de muestras en cerdos vivos. En los cerdos de los grupos G1 y G6 se obtuvieron muestras de sangre para hemograma completo a los $0,3,7,11,15,19,23,27,31$ y $35 \mathrm{dpi}$, a través de una punción en la vena cava craneal utilizando tubos al vacío de $5 \mathrm{~mL}$ con anticoagulante EDTA (VACUTAINER®, Becton Dickinson Vacutainer Systems). Adicionalmente, se obtuvieron muestras de sangre $(5 \mathrm{~mL})$ para aislamiento viral utilizando tubos de $10 \mathrm{~mL}$ sin anticoagulante (VACUTAINER ${ }^{\circledR}$, Becton Dickinson Vacutainer Systems).

En los animales de los grupos contacto (G2, G3, G4 y G5) se obtuvieron muestras de sangre a los 0,5 y 12 días postcontacto (dpc) para hemograma completo y aislamiento viral utilizando el mismo procedimiento que para G1 y G6.

Necropsia y toma de muestras en cerdos sacrificados. Los cerdos de cada uno de los grupos contacto fueron sacrificados a los 12 dpc y los animales de G1 y G6 a los 35 dpi. Para el sacrificio, los animales fueron sedados con acepromazina al 1\% (PACIFOR ${ }^{2}$, Laboratorio Drag Pharma Invetec) intramuscular $(0,5 \mathrm{mg} / \mathrm{kg})$, y se eutanasiaron con tiopental sódico diluido al $10 \%$ (Laboratorio Bestpharma S. A.) endovenoso (50 mg/kg).

Durante la necropsia de cada uno de los cerdos control, inoculados y contactos, se tomaron muestras de cornete nasal, tonsila (lado derecho), nódulo linfático submandibular, pulmón (lóbulo cardiaco derecho) y bazo, las cuales fueron fijadas en formol al $10 \%$ y procesadas para histopatología e inmunohistoquímica. Por otra parte, se obtuvieron muestras de la tonsila izquierda y del lóbulo craneal derecho del pulmón para aislamiento viral.

\section{Procesamiento y análisis de las muestras}

Hematología: las muestras de sangre fueron procesadas para la determinación del hematocrito (\%), hemoglobina (g/dL) y recuento total y diferencial de leucocitos (total células/ $\mu \mathrm{L}$ ) utilizando un contador hematológico automático (Hycel Diagnostic, Celly). Con el plasma obtenido se midieron las proteínas plasmáticas totales $(\mathrm{g} / \mathrm{dL})$ y los niveles sanguíneos de fibrinógeno $(\mathrm{g} / \mathrm{dL})$ utilizando el método de precipitación por calor de acuerdo a lo descrito Schalm y col (1975).

Estudio histopatológico: los tejidos obtenidos en las necropsias fueron fijados en formol tamponado al $10 \%$ por un período de 24 horas y luego fueron procesados utilizando un procesador Shandon (modelo Citadel 1000) con bomba de vacío y un Centro de Inclusión Microm (modelo AP280-2). De los bloques de parafina se realizaron cortes de $4 \mu \mathrm{m}$ con un micrótomo Leica (modelo RM 2045), los que fueron teñidos con hematoxilina y eosina. Posteriormente los tejidos fueron observados y fotografiados con un fotomicroscopio (Zeiss, Axioskop 50). Las lesiones histopatológicas en pulmón fueron re- 
gistradas y clasificadas como: sin lesiones; neumonía intersticial leve y focal; neumonía intersticial moderada y multifocal; neumonía intersticial moderada y difusa; neumonía intersticial severa y difusa.

Los órganos linfoides fueron evaluados de la siguiente forma: sin lesiones; hiperplasia leve de folículos linfoides, sin depleción ni necrosis celular; hiperplasia moderada de folículos con necrosis celulares aisladas; hiperplasia moderada de folículos con necrosis celulares multifocales y depleción linfoide leve; hiperplasia severa de folículos con necrosis celulares abundantes, difusas y depleción linfoide de moderada a severa intensidad.

Estudio inmunohistoquímico (IHQ): los tejidos fueron procesados de acuerdo a lo descrito por Quezada y col (2005). A partir de los tejidos incluidos en parafina se realizaron cortes seriados, los cuales fueron montados en portaobjetos cubiertos con poli-L-lisina. Para la demostración del antígeno viral se utilizó el método del Complejo Avidina-Biotina (ABC Kit Vector Laboratories, Burlingame, CA, USA), utilizando el anticuerpo monoclonal SDOW-17 a una dilución de 1:500 en PBS. Las muestras fueron reveladas utilizando el cromógeno DAB (3.3'- diaminobenzidine tetrahydro-chloride) (Sigma Chemical Co., St. Louis, MO, USA) y Nova Red (Vector Laboratories, Burlingame, CA, USA) y, finalmente, fueron contrateñidas con hematoxilina de Mayer. Las muestras fueron observadas y fotografiadas en un fotomicroscopio. Para su evaluación se realizó un análisis semicuantitativo a través del conteo de células marcadas en 5 campos homogéneos por muestra, seleccionados al azar. El nivel de infección de los tejidos fue evaluado a partir de la sumatoria de los campos, de acuerdo a la siguiente pauta: $0=0$ a 5 células inmunoteñidas (negativo); $1=5$ a 10 células inmunoteñidas; $2=11$ a 30 células inmunoteñidas; $3=31$ a 100 células inmunoteñidas; 4=> 100 células inmunoteñidas (modificado de Halbur y col 1996a).

Aislamiento viral: se sembraron y cultivaron células MARC 145 en placas de 24 pocillos a una concentración de 100.000 células/mL, utilizando Medio Esencial Mínimo (MEM) con sales de Earle, $10 \%$ de suero fetal bovino, gentamicina y anfotericina $\mathrm{B}$, e incubadas por 24 horas aproximadamente a $37{ }^{\circ} \mathrm{C}$ con una atmósfera de $5 \%$ de $\mathrm{CO}_{2}$ y $92 \%$ de humedad relativa (HR). A partir de las muestras de sangre se obtuvo por centrifugación la costra flogística, la cual fue resuspendida en $400 \mu \mathrm{lde}$ suero proveniente de las mismas muestras, y luego se inocularon $200 \mu \mathrm{l}$ sobre el estrato celular. En las muestras de tejidos se realizaron cortes de $0,5 \mathrm{~cm}^{3}$, los cuales fueron macerados, suspendidos en $5 \mathrm{~mL}$ de MEM y centrifugados con el fin de obtener el sobrenadante con el cual se inocularon $300 \mu \mathrm{l}$ sobre el estrato celular. Posteriormente las placas fueron nuevamente incubadas (60 minutos a $37^{\circ} \mathrm{C}$, con $5 \%$ de $\mathrm{CO}_{2}$ y $92 \%$ HR), se eliminó el sobrenadante y se repuso medio de mantención (MEM con $2 \%$ de suero fetal bovino, gentamicina y anfotericina B). Finalmente las placas fueron incubadas por 96 horas, bajo las mismas condiciones descritas para el proceso anterior. Las células inoculadas fueron observadas para determinar la presencia de efecto citopático. El procedimiento de aislamiento viral se realizó con un número de 3 pasajes sucesivos, cuando fue evidente el efecto citopático. Entre cada pasaje en células las muestras se congelaron a $-20{ }^{\circ} \mathrm{C}$ y se descongelaron a temperatura ambiente al menos 3 veces, con el fin de lisar las células y liberar los viriones.

Análisis estadístico. Los resultados del estudio hematológico fueron analizados a través de un análisis de varianza de muestras repetidas para determinar diferencias entre las medias de los grupos, con un nivel de confianza del $95 \%$.

\section{RESULTADOS}

Antes del ingreso de los animales a las unidades experimentales los cerdos de todos los grupos resultaron negativos a la presencia de anticuerpos anti PRRS a través de ELISA y el genoma viral no fue detectado por RT-nPCR.

Aspectos clínicos y hematológicos. Los cerdos de G1, presentaron fiebre entre los 3 y $4 \mathrm{dpi}$, alcanzando un promedio de $40{ }^{\circ} \mathrm{C}$, manteniendo una temperatura más elevada que el grupo control por casi todo el período experimental. Los animales del grupo G6 no presentaron fiebre durante todo el período experimental.

Los cerdos inoculados sufrieron retraso en el crecimiento, lo que se manifestó en una disminución de 3,3 $\mathrm{kg}$ en el peso promedio en relación a los cerdos de G6 a los 35 dpi. Adicionalmente, los animales de G1 presentaron letargia moderada, secreción conjuntival y edema de los párpados a partir de la segunda semana post inoculación hasta el final del experimento; sin embargo, no se observó sintomatología respiratoria. En los cerdos de los grupos contacto G2, G3, G4, G5 y el grupo control G6, no se registró fiebre y no se observaron signos ni síntomas clínicos.

Desde el punto de vista hematológico, en los cerdos de G1 se observó una disminución no significativa $(\mathrm{P}>0,05)$ del hematocrito y de los niveles de hemoglobina bajo los parámetros normales entre los 3 y 31 dpi, la que fue especialmente marcada entre los 19 y 31 dpi. Del mismo modo, en los animales de G6 se observó una disminución, no significativa ( $\mathrm{P}>0,05)$, en el hematocrito a los 11, 23 y 27 dpi, mostrando un patrón similar al de G1. El resto de los parámetros hematológicos estuvieron dentro de los rangos normales para esta edad en la especie, descrita por Friendship y Henry (1992) en todos los grupos de animales. 


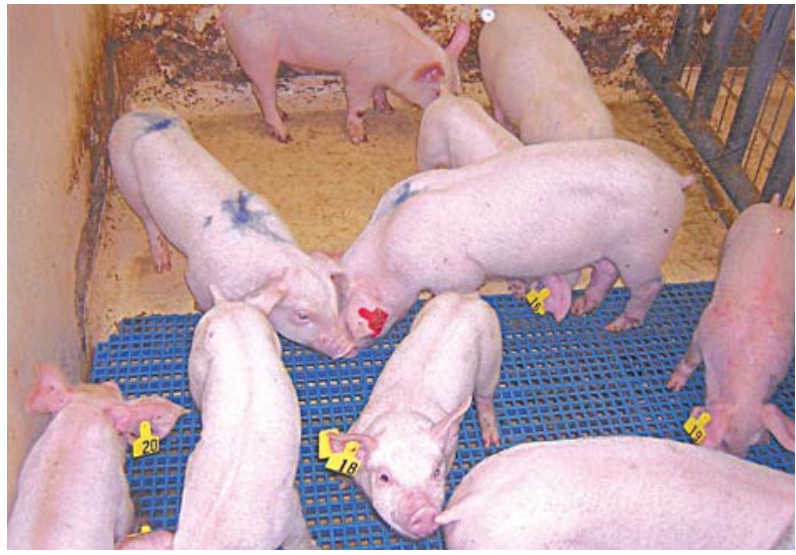

Figura 1. Contacto directo entre los cerdos del grupo inoculado (G1) y los cerdos del grupo contacto (G5, crotal amarillo).

Direct contact between the pigs of the inoculated group (G1) and the pigs of the contact group (G5, yellow ear tag).

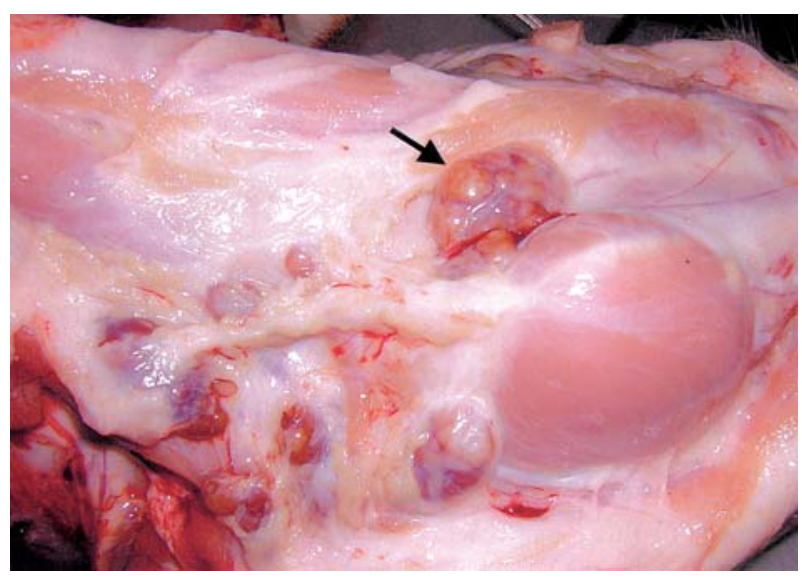

Figura 2. Aumento de tamaño de los nódulos linfáticos submandibulares (flecha) y otros nódulos linfáticos de la región cervical en un cerdo del grupo contacto (G3), sacrificado a los 12 días postcontacto con G1.

Enlargement of the submandibular lymph node (arrow) and other lymph nodes of the cervical region in a pig of the contact group (G3), slaughtered at 12 days post contact with G1.

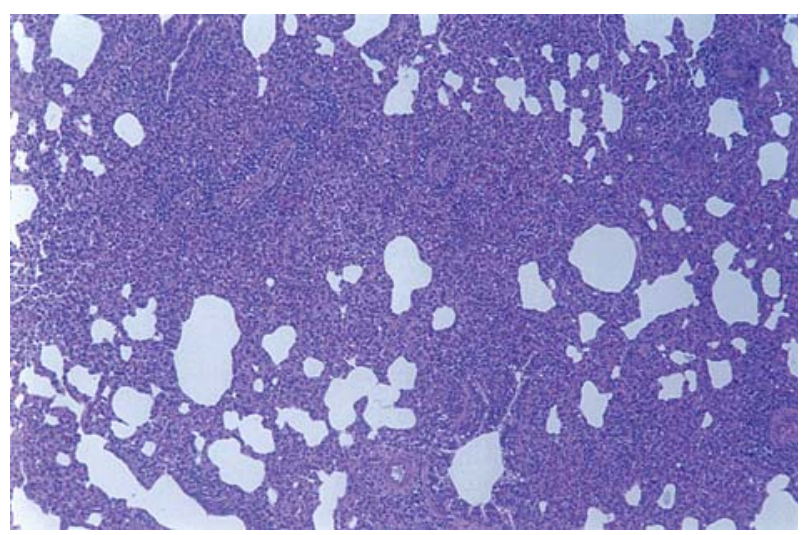

Figura 3. Pulmón con neumonía intersticial de un cerdo de G1. H-E; 200X.

Lung with interstitial pneumonia in a pig of G1. H-E; 200X.

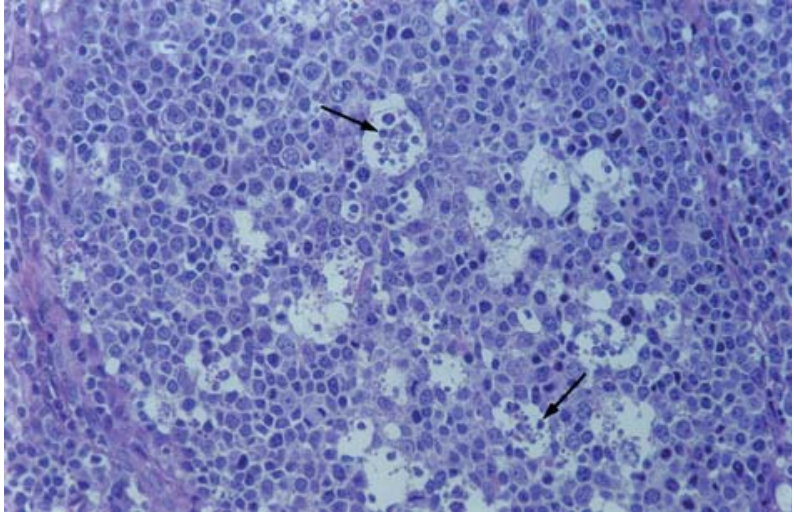

Figura 4. Tonsila de un cerdo de G3, con necrosis linfoides (flechas) en el centro germinal de un folículo. H-E; 400X.

Tonsil of a G3 pig, with lymphoid necrosis (arrows) in a germinal center of a follicle. H-E; 400X.

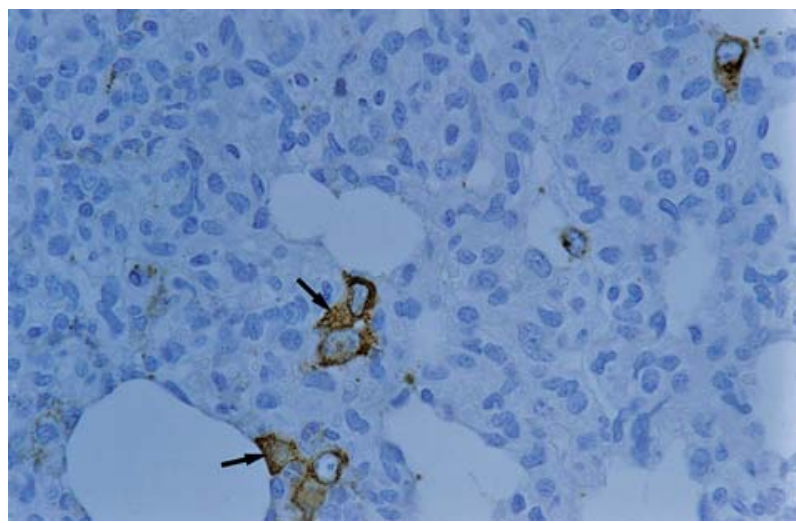

Figura 5. Septos alveolares gruesos conteniendo macrófagos inmunoteñidos (flechas) con anticuerpo SDOW 17 en un cerdo de G2. Complejo ABC, contrateñido con hematoxilina. $630 X$.

Thick alveolar septa, containing macrophages, immunostained (arrows) with SDOW 17 antibody from a G2 pig. ABC Complex, counterstained with haematoxylin. 630X.

\section{Aspectos patológicos}

Lesiones macroscópicas: cerdos inoculados (G1) y Controles (G6): en pulmón, tres de los cerdos inoculados presentaron áreas focales de atelectasia, principalmente en el lóbulo intermedio derecho (1/5) y en la porción craneal del lóbulo diafragmático izquierdo (2/5). Todos los cerdos de este grupo presentaron linfoadenopatía generalizada de grado moderado a severo, especialmente en nódulos linfáticos submandibulares, traqueobronquiales, mediastínicos e inguinales. En un cerdo se observaron estructuras quísticas subcapsulares en el nódulo linfático mesentérico. De forma menos constante se observaron ascitis e hidropericardio leve (1/5). Los cerdos del grupo control (G6) no presentaron lesiones a la necropsia. 
Cerdos contacto (G2, G3, G4 y G5): en el grupo contacto G2 todos los cerdos tenían linfoadenopatía generalizada con mayor compromiso de los nódulos linfáticos submandibulares, inguinales y mesentéricos. Un animal presentó edema periocular. En G3, tres animales tenían pelaje hirsuto, dos presentaron edema periocular bilateral y linfoadenopatía generalizada (figura 2). Todos los cerdos de G4 y G5 tenían linfoadenopatía leve; por otra parte, en un cerdo de G4 y en uno de G5 se observó atelectasia focal en los lóbulos diafragmáticos.

Lesiones microscópicas: las principales lesiones histopatológicas del pulmón y órganos linfoides se resumen en el cuadro 1.

Cuadro 1. Principales lesiones microscópicas en pulmón, tonsila, nódulo linfático submandibular y bazo de los cerdos de cada uno de los diferentes grupos experimentales (G1, G2, G3, G4, G5 y G6), en relación al total de cerdos por grupo.

Main microscopic lesions in the lung, tonsil, submandibular lymph node and spleen of the pigs of each of the different experimental groups (G1, G2, G3, G4, G5 and G6), in relation to the total pigs per group.

Tejido Clasificación de las lesiones
$\mathrm{N}^{\circ}$ de cerdos afectados/

Total de cerdos analizados por grupo

\begin{tabular}{|c|c|c|c|c|c|c|c|}
\hline & & G1 & $\mathrm{G} 2$ & G3 & G4 & G5 & G6 \\
\hline \multirow{5}{*}{ Pulmón } & Sin lesiones & $0 / 5$ & $0 / 5$ & $1 / 5$ & $1 / 5$ & $0 / 5$ & $2 / 5$ \\
\hline & Neumonía intersticial leve y focal & $0 / 5$ & $4 / 5$ & $4 / 5$ & $2 / 5$ & $5 / 5$ & $3 / 5$ \\
\hline & Neumonía intersticial moderada, multifocal & $1 / 5$ & $1 / 5$ & $0 / 5$ & $1 / 5$ & $0 / 5$ & $0 / 5$ \\
\hline & Neumonía intersticial moderada, difusa & $1 / 5$ & $0 / 5$ & $0 / 5$ & $1 / 3$ & $0 / 5$ & $0 / 5$ \\
\hline & Neumonía intersticial severa, difusa & $3 / 5$ & $0 / 5$ & $0 / 5$ & $0 / 5$ & $0 / 5$ & $0 / 5$ \\
\hline \multirow{5}{*}{ Tonsila } & Sin lesiones & $0 / 5$ & $0 / 5$ & $1 / 5$ & $0 / 5$ & $0 / 5$ & $1 / 5$ \\
\hline & $\begin{array}{l}\text { Hiperplasia leve de folículos linfoides, sin depleción } \\
\text { ni necrosis celular }\end{array}$ & $1 / 5$ & $3 / 5$ & $2 / 5$ & $3 / 5$ & $3 / 5$ & $4 / 5$ \\
\hline & $\begin{array}{l}\text { Hiperplasia moderada de folículos con necrosis } \\
\text { celulares aisladas }\end{array}$ & $2 / 5$ & $2 / 5$ & $2 / 5$ & $2 / 5$ & $2 / 5$ & $0 / 5$ \\
\hline & $\begin{array}{l}\text { Hiperplasia moderada de folículos con necrosis } \\
\text { celulares multifocales y depleción linfoide leve }\end{array}$ & $1 / 5$ & $0 / 5$ & $0 / 5$ & $0 / 5$ & $0 / 5$ & $0 / 5$ \\
\hline & $\begin{array}{l}\text { Hiperplasia severa de folículos con necrosis celulares } \\
\text { abundantes difusas y depleción linfoide de moderada } \\
\text { a severa intensidad }\end{array}$ & $1 / 5$ & $0 / 5$ & $0 / 5$ & $0 / 5$ & $0 / 5$ & $0 / 5$ \\
\hline \multirow{5}{*}{$\begin{array}{l}\text { Nódulo linfático } \\
\text { submandibular }\end{array}$} & Sin lesiones & $0 / 5$ & $0 / 5$ & $0 / 5$ & $0 / 5$ & $0 / 5$ & $0 / 5$ \\
\hline & $\begin{array}{l}\text { Hiperplasia leve de folículos linfoides, sin depleción } \\
\text { ni necrosis celular }\end{array}$ & $0 / 5$ & $1 / 5$ & $3 / 5$ & $3 / 5$ & $0 / 5$ & $4 / 5$ \\
\hline & $\begin{array}{l}\text { Hiperplasia moderada de folículos con necrosis } \\
\text { celulares aisladas }\end{array}$ & $1 / 5$ & $2 / 5$ & $1 / 5$ & $1 / 5$ & $3 / 5$ & $1 / 5$ \\
\hline & $\begin{array}{l}\text { Hiperplasia moderada de folículos con necrosis } \\
\text { celulares multifocales y depleción linfoide leve }\end{array}$ & $2 / 5$ & $1 / 5$ & $1 / 5$ & $0 / 5$ & $1 / 5$ & $0 / 5$ \\
\hline & $\begin{array}{l}\text { Hiperplasia severa de folículos con necrosis celulares } \\
\text { abundantes difusas y depleción linfoide de moderada } \\
\text { a severa intensidad }\end{array}$ & $2 / 5$ & $1 / 5$ & $0 / 5$ & $1 / 5$ & $1 / 5$ & $0 / 5$ \\
\hline \multirow{5}{*}{ Bazo } & Sin lesiones & $0 / 5$ & $0 / 5$ & $0 / 5$ & $0 / 5$ & $0 / 5$ & $2 / 0$ \\
\hline & $\begin{array}{l}\text { Hiperplasia leve de folículos linfoides, sin depleción } \\
\text { ni necrosis celular }\end{array}$ & $4 / 5$ & $4 / 5$ & $3 / 5$ & $4 / 5$ & $4 / 5$ & $3 / 5$ \\
\hline & $\begin{array}{l}\text { Hiperplasia moderada de folículos con necrosis } \\
\text { celulares aisladas }\end{array}$ & $1 / 5$ & $1 / 5$ & $2 / 5$ & $0 / 5$ & $1 / 5$ & $0 / 5$ \\
\hline & $\begin{array}{l}\text { Hiperplasia moderada de folículos con necrosis } \\
\text { celulares multifocales y depleción linfoide leve }\end{array}$ & $0 / 5$ & $0 / 5$ & $0 / 5$ & $1 / 3$ & $0 / 5$ & $0 / 5$ \\
\hline & $\begin{array}{l}\text { Hiperplasia severa de folículos con necrosis celulares } \\
\text { abundantes difusas y depleción linfoide de moderada } \\
\text { a severa intensidad }\end{array}$ & $0 / 5$ & $0 / 5$ & $0 / 5$ & $0 / 5$ & $0 / 5$ & $0 / 5$ \\
\hline
\end{tabular}


Cerdos inoculados (G1) y Controles (G6): todos los cerdos de G1 presentaron neumonía intersticial caracterizada por infiltrados septales linfohistiocitarios de moderada a severa intensidad y de distribución multifocal a difusa (figura 3). Además, en tres animales se observó hiperplasia del tejido linfoide peribronquiolar e infiltrados perivasculares intersticiales. En los cornetes nasales se observaron infiltrados linfohistiocitarios focales y multifocales subepiteliales de moderada a severa intensidad (rinitis linfohistiocitaria) con pérdida focal de cilios desde el epitelio en todos los cerdos. En tonsilas, nódulo linfático submandibular y bazo se observó hiperplasia de centros germinales de los folículos linfoides con abundantes mitosis y aumento del número de linfoblastos. También se detectaron necrosis celulares dentro de los folículos, caracterizadas por la presencia de grupos de células picnóticas y detritus celulares (figura 4) asociadas en algunos casos con depleción linfoide leve. La mayor intensidad de estos hallazgos se presentó en tonsilas y nódulo linfático submandibular. En bazo estas lesiones fueron de menor intensidad en folículos y vainas linfoides periarteriolares (PALS) de la pulpa blanca.

En los cerdos controles (G6) sólo se observaron infiltrados linfohistiocitarios leves de septos en tres cerdos. En los cornetes nasales se vieron infiltrados linfohistiocitarios multifocales de leve a moderada intensidad en todos los cerdos. Los tejidos linfoides presentaron escasa actividad de centros germinales con necrosis linfoides aisladas y ausencia de depleción.

Cerdos Contacto (G2, G3, G4 y G5): los tejidos linfoides de estos cerdos presentaron hiperplasia de centros germinales y necrosis linfoides aisladas. Estos cerdos también tenían rinitis linfohistiocitarias, las que fueron más intensas en G2 y G3. Los 4 grupos de cerdos presentaron neumonía intersticial, la cual fue más intensa en los cerdos de G2 y G3, disminuyendo en intensidad en G4 y G5. Además, se observó hiperplasia de teji- do linfoide de carácter leve en los cerdos de los grupos G2, G3 y G4.

Inmunohistoquímica: el cuadro 2 resume el número de tejidos en los cuales fueron detectados antígenos del VPRRS y la cantidad estimada de antígenos (puntaje promedio) en cada uno de los grupos experimentales.

Cerdos inoculados (G1) y Controles (G6): el antígeno viral fue detectado en pulmón (1/5), cornete nasal (1/5), linfonódulo submandibular y bazo (4/5) en el grupo de cerdos inoculados (G1); sin embargo, la cantidad de células inmunoteñidas fue escasa e inconstante. En el pulmón, el antígeno viral fue detectado principalmente en macrófagos alveolares, septales, perivasculares y en la lámina propia de bronquios y bronquíolos, con escasa cantidad de células marcadas. En la mucosa nasal se presentaron células inmunoteñidas con baja intensidad, principalmente en macrófagos localizados en infiltrados inflamatorios focales de la lámina propia e intraepiteliales. En los órganos linfoides, el bazo presentó la mayor inmunorreacción, siendo el antígeno viral detectado en macrófagos de la pulpa blanca y roja. En los cerdos de G6 sólo se detectaron algunas células positivas aisladas en el bazo ( $<5$ células inmunoteñidas); sin embargo, éstas fueron consideradas inespecíficas y calificadas como negativas de acuerdo a la pauta de evaluación.

Cerdos Contacto (G2, G3, G4 y G5): estos grupos de animales presentaron mayor cantidad de tejidos inmunoteñidos respecto a G1. En todos los grupos se detectó antígeno viral en pulmón (figura 5), cornete nasal, tonsila, nódulo linfático submandibular y bazo, en al menos 1 cerdo por grupo a excepción de los cornetes nasales y nódulo linfático submandibular en los animales de G2. Por otro lado, todos los cerdos de G3 presentaron inmunorreacción a excepción de un animal en el cual no se detectó antígeno en cornete nasal. Del mismo modo, estos animales presentaron la mayor canti-

Cuadro 2. Número de cerdos con tejidos positivos a IHQ en relación al total de cerdos analizados por grupo y el promedio estimado del puntaje de acuerdo a la cantidad de antígeno de VPRRS detectado.

Number of pigs with IHQ positive tissues in relation to the total of pigs analyzed per group and the estimated average of the score according to the amount of detected antigen of VPRRS.

\begin{tabular}{lcccccccccccc}
\hline Tejidos & G1 & $\begin{array}{c}\bar{X} \\
\text { Score }\end{array}$ & G2 & $\begin{array}{c}\bar{X} \\
\text { Score }\end{array}$ & G3 & $\begin{array}{c}\bar{X} \\
\text { Score }\end{array}$ & G4 & $\begin{array}{c}\bar{X} \\
\text { Score }\end{array}$ & G5 & $\begin{array}{c}\bar{X} \\
\text { Score }\end{array}$ & $\begin{array}{c}\text { G6 } \\
\text { Score }\end{array}$ \\
\hline Pulmón & $1 / 5$ & 0,2 & $1 / 5$ & 0,2 & $5 / 5$ & 2,2 & $3 / 5$ & 0,6 & $3 / 5$ & 0,6 & $0 / 5$ & 0 \\
Cornete & $1 / 5$ & 0,2 & $0 / 5$ & 0 & $4 / 5$ & 2 & $4 / 5$ & 1,4 & $1 / 5$ & 0,4 & $0 / 5$ & 0 \\
Tonsila & $0 / 5$ & 0 & $1 / 5$ & 0,2 & $5 / 5$ & 2,4 & $4 / 5$ & 0,8 & $3 / 5$ & 0,6 & $0 / 5$ & 0 \\
Nódulo linfático & $1 / 5$ & 0,2 & $0 / 5$ & 0 & $5 / 5$ & 2,2 & $1 / 5$ & 0,2 & $1 / 5$ & 0,2 & $0 / 5$ & 0 \\
submandibular & $4 / 5$ & 1,6 & $4 / 5$ & 1 & $5 / 5$ & 2,6 & $3 / 5$ & 0,6 & $5 / 5$ & 1,4 & $0 / 5$ & 0 \\
Bazo & & & & & & & & & & &
\end{tabular}


dad de células marcadas en relación a los restantes grupos contacto.

Respecto a la distribución del antígeno, en pulmón fue detectado en macrófagos alveolares, septales, perivasculares y en la lámina propia de bronquios y bronquiolos. En la mucosa nasal se observaron células positivas en macrófagos intersticiales y perivasculares de la lámina propia y en macrófagos intraepiteliales. En los órganos linfoides, la inmunorreacción se observó en células localizadas en los centros germinales de los folículos linfoides y en el tejido linfoide difuso de la tonsila y nódulo linfático submandibular. Las células positivas tenían citoplasma amplio, similares a macrófagos, o de forma estrellada e irregular con prolongaciones citoplasmáticas, similares a células dendríticas. En las tonsilas, el antígeno viral fue detectado dentro y alrededor del epitelio de la cripta, en centros germinales de folículos y en el tejido linfoide difuso. En el nódulo linfático submandibular, el antígeno se detectó en macrófagos y células dendríticas dentro de los centros germinales activos y en restos celulares de áreas foliculares de necrosis dentro del folículo. Además, se observó un patrón multifocal de inmunotinción en el tejido linfoide difuso interfolicular. El bazo presentó los patrones de inmunotinción más evidentes y generalmente de mayor intensidad. Las células marcadas se localizaron fundamentalmente en folículos linfoides, PALS y en la pulpa roja.

Aislamiento viral: el VPRRS fue aislado desde el suero de los cerdos de G1 entre los 3 y 23 dpi. Los animales de G6 fueron negativos al aislamiento durante todo el período experimental. En los cerdos de los grupos contacto, el virus fue aislado desde el suero en G2 y G3 a los 5 dpc (2/5 y $3 / 5$, respectivamente) y a los $12 \mathrm{dpc}(4 / 5$ y $5 / 5$, respectivamente); sin embargo, no fue aislado de ninguno de los cerdos de G4 y G5 (figura 6). Por otra parte, el virus fue aislado desde la tonsila en los cerdos de G1, G2, G3, G4 y G5, y en pulmón no fue aislado desde ningún cerdo de G4, como lo muestra el cuadro 3 .

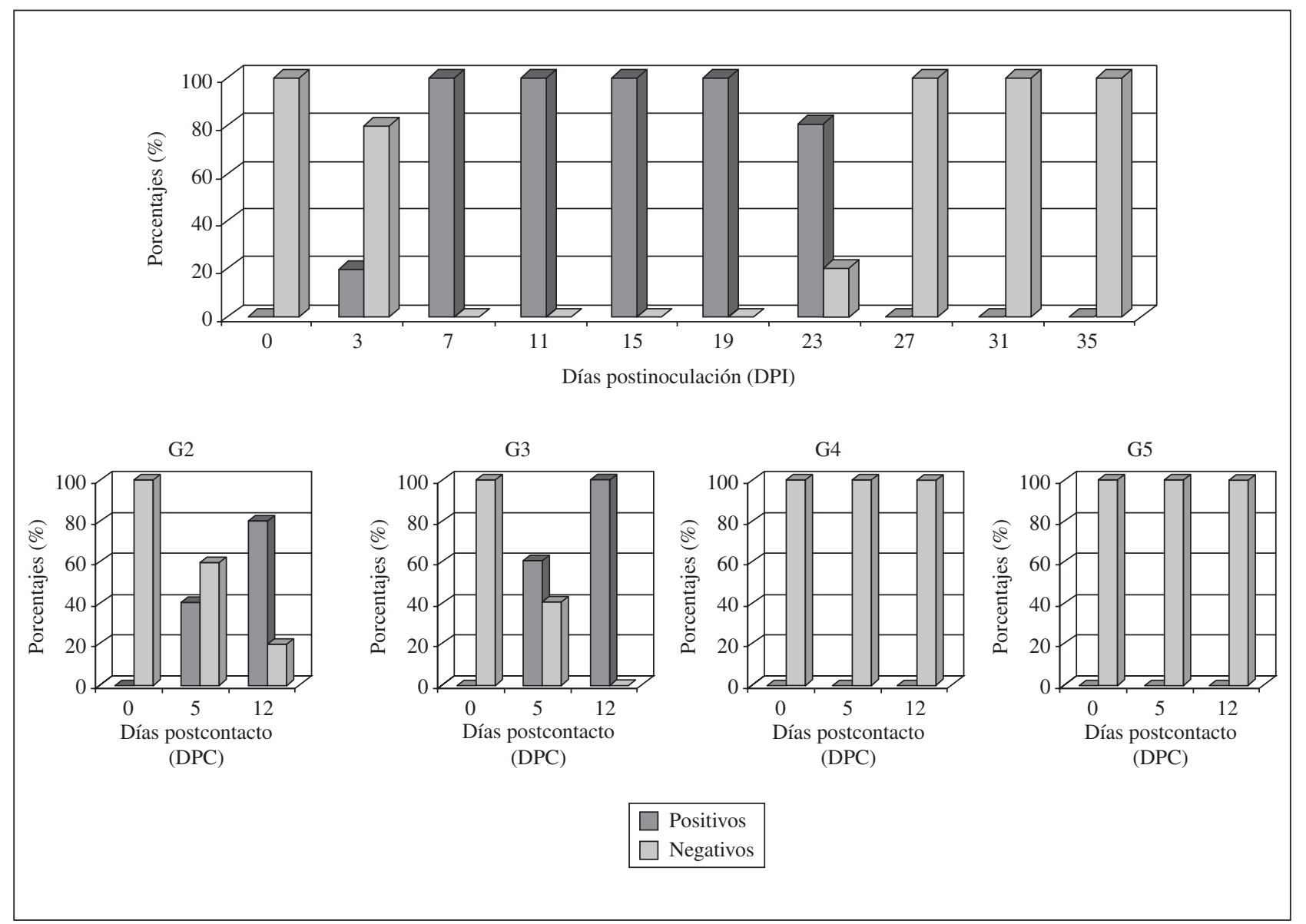

Figura 6. Aislamiento viral desde el suero de cerdos inoculados (G1) durante los diferentes días de muestreo postinoculación y de los cerdos de los grupos contacto (G2, G3, G4, G5) durante los diferentes días de muestreo postcontacto.

Viral isolation from the serum of inoculated pigs (G1) during the different days of sampling post inoculation and of pigs of the contact groups (G2, G3, G4, G5) during the different days of post contact sampling. 
Cuadro 3. Aislamiento viral desde tonsila y pulmón de los cerdos de todos los grupos experimentales.

Viral isolation from tonsils and lungs of the pigs of all the experimental groups.

\begin{tabular}{llc}
\hline Grupos & \multicolumn{2}{c}{$\begin{array}{c}\mathrm{N}^{\circ} \text { de cerdos positivos/ } \\
\mathrm{N}^{\circ} \text { de cerdos analizados }\end{array}$} \\
\cline { 2 - 3 } & Tonsila & Pulmón \\
\hline & & \\
G1 & $3 / 5$ & $2 / 5$ \\
G2 & $4 / 5$ & $3 / 5$ \\
G3 & $2 / 5$ & $2 / 5$ \\
G4 & $2 / 5$ & $0 / 5$ \\
G5 & $5 / 5$ & $5 / 5$ \\
G6 & $0 / 5$ & $0 / 5$ \\
\hline
\end{tabular}

\section{DISCUSION}

Estudios experimentales previos realizados con el aislado chileno del VPRRS indican que éste se disemina en el organismo de forma multisistémica, aunque las manifestaciones clínico-patológicas fueron leves e inconstantes y la viremia relativamente más corta en cerdos inoculados experimentalmente, lo cual sugiere que este virus sería de baja patogenicidad (Quezada y col 2005, Ramírez y col 2006) y se comportaría de forma diferente a algunos aislados norteamericanos altamente patógenos (Rossow y col 1994, 1995, Halbur y col $\left.1996^{\mathrm{b}}\right)$.

Desde el punto de vista clínico, en este estudio no se observó sintomatología respiratoria y sólo se detectaron síntomas leves e inespecíficos en los cerdos inoculados y en todos los grupos contacto. Estos hallazgos fueron similares a los descritos por Ramírez y col (2006), corroborando de cierta forma que este aislado no se manifiesta clínicamente con sintomatología respiratoria como la descrita en varios estudios de patogenicidad con aislados norteamericanos (Rossow y col 1994, 1995, Halbur y col $\left.1996^{\mathrm{b}}\right)$.

Por otro lado, sólo se registró fiebre durante un breve período ( 2 días) en los cerdos de G1, lo cual difiere a lo descrito en estudios previos con el aislado chileno, donde no se observó aumento de la temperatura corporal en ningún cerdo inoculado experimentalmente durante un período de 21 días (Ramírez y col 2006). La duración de la fiebre en los cerdos inoculados con el aislado chileno también presenta diferencias al compararlo con otro estudio realizado con un aislado norteamericano de mayor patogenicidad, en el cual se registró aumento de la temperatura corporal entre los 2 y 17 dpi en cerdos inoculados de 4 semanas de edad (Rossow y col 1994).

Del mismo modo, no se registraron alteraciones importantes en los parámetros hematológicos, aunque en los cerdos de G1 se observó una tendencia del hematocrito y niveles de hemoglobina a disminuir bajo los rangos normales especialmente durante la segunda y tercera semana postinoculación. En cerdos inoculados experimentalmente con aislados altamente patógenos se ha demostrado una disminución en el hematocrito y del recuento de eritrocitos especialmente marcado desde los 10 dpi hasta el final de la experiencia a los $21 \mathrm{dpi}$ (Halbur y col 2002). En este estudio no se puede atribuir con total certeza la disminución del hematocrito al efecto del virus, ya que en los cerdos de G6 se observó una tendencia similar aunque menos intensa. Esta disminución podría estar asociada a la alta frecuencia de muestreo de sangre a una edad del animal en la cual la respuesta celular de la médula ósea no está completamente madura, como lo ha descrito Thorn (2000). El hecho de que no se haya registrado un descenso en el hematocrito de los cerdos contacto estaría relacionado con una menor frecuencia de muestreo y un período experimental más corto con respecto a los cerdos de G1 y G6. Por otra parte, en este estudio no se registraron alteraciones en el recuento de leucocitos, a diferencia de lo observado por otros autores que han descrito leucopenia asociada con linfopenia especialmente dentro de la primera semana postinfección (Rossow y col 1994, Nilsen y Bøtner 1997, Halbur y col 2002).

Desde el punto de vista patológico, la alteración más importante fue la linfoadenopatía observada en los cerdos de G1, G2 y G3 y con menor intensidad en G4 y G5. Este hallazgo ha sido descrito frecuentemente y durante estadios tempranos de la enfermedad en cerdos infectados con VPRRS (Rossow y col 1994, 1995, Halbur y col $\left.1996^{b}\right)$. En el pulmón no se registraron lesiones macroscópicas importantes asociadas a la enfermedad en ningún cerdo de G1 ni en los grupos contacto, lo cual concuerda con lo descrito en estudios previos realizados con el aislado chileno (Ramírez y col 2006). Sólo se observaron áreas focales de atelectasia en algunos cerdos de G1, G4 y G5, lo cual difiere a lo descrito en cerdos infectados con aislados altamente patógenos donde se describe hasta un 54,2\% de consolidación de parénquima pulmonar (Halbur y col 1996 b). Histopatológicamente, se observaron lesiones más específicas asociadas a infección viral. En todos los cerdos de G1 y de los grupos contacto había neumonía intersticial linfohistiocitaria, aunque la intensidad de las lesiones fue de menor frecuencia y severidad en los grupos contacto. En cerdos inoculados con aislados norteamericanos la neumonía intersticial fue de mayor intensidad entre los 14 y $21 \mathrm{dpi}$ y se caracterizó por la presencia de severos infiltrados inflamatorios septales, detritus celulares alveolares e hiperplasia multifocal de neumocitos tipo 2 (Rossow y col 1995, Halbur y col 1996 b). Aunque en cerdos inoculados con el aislado chileno del VPRRS también se observó mayor intensidad de lesiones pulmonares entre los 14 dpi y 21 dpi (Quezada y col 2005, Ramírez y col 2006), 
éstas no presentaron la severidad descrita anteriormente para aislados norteamericanos altamente patógenos. Del mismo modo, la intensidad de la neumonía intersticial en los cerdos de G1 a los 35 dpi fue menor en comparación a la descrita en estudios previos con el aislado chileno a los 14 y $21 \mathrm{dpi}$, lo cual puede deberse a que a los 35 dpi las lesiones pulmonares tienden a remitir.

Por otra parte, la presencia de hiperplasia de centros germinales y necrosis linfoides intrafoliculares fue un hallazgo frecuente en los cerdos de G1 y en todos los grupos contacto, y la mayor intensidad de estas lesiones se presenta en el nódulo linfático submandibular. Estos hallazgos han sido descritos en cerdos inoculados experimentalmente y la presencia de múltiples necrosis linfoides en los folículos puede indicar que el virus replica en estos tejidos (Rossow y col 1994) o puede ser asociado a un efecto secundario mediado por citoquinas inflamatorias. Desde este punto de vista, Sur y col (1998) demostraron a través de métodos inmunohistoquímicos que el VPRRS induce apoptosis en pulmón y tejidos linfoides, aunque la mayoría de las células apoptóticas no estaban infectadas, sugiriendo que existirían métodos indirectos en la inducción de este fenómeno. Posteriormente, Labarque y col (2003) describieron que algunas citoquinas, como IL-1, IL-10 y FNT \pm , estarían involucradas en la inducción de apoptosis en monocitos y macrófagos intersticiales no infectados del pulmón de cerdos inoculados con un aislado europeo del VPRRS. En este estudio las características morfológicas de los detritus celulares observados en los tejidos linfoides son compatibles con apoptosis; sin embargo, este fenómeno no fue demostrado a través de métodos específicos.

Los hallazgos clínico patológicos observados en este estudio son concordantes con las observaciones realizadas en estudios previos con el aislado chileno (Quezada y col 2005, Ramírez y col 2006) y demuestran de cierta forma que este virus se comporta como un aislado de baja patogenicidad en condiciones experimentales.

La transmisión y capacidad de infección del aislado chileno del VPRRS fue demostrada a través de inmunohistoquímica y aislamiento viral. Tanto los cerdos de G1 como los cerdos de los grupos contacto presentaron células positivas a la presencia de antígenos virales en pulmón y tejidos linfoides. En los cerdos de G1, la intensidad y constancia de la inmunotinción fue baja en pulmón, registrándose sólo un cerdo positivo; sin embargo, en G3, G4 y G5 la constancia e intensidad fue mayor en pulmón y tejidos linfoides, especialmente en los cerdos de G3. Los hallazgos observados en el pulmón y bazo demuestran que no existe una relación clara entre la intensidad de lesiones histopatológicas y la presencia de antígenos virales en los tejidos a pesar que éste se considera citopático, según lo descrito por Suárez (2000). La escasa reacción a la IHQ observada en los pulmones de los cerdos de G1, y la mayor reactividad en bazo, nódulos linfáticos y tonsila, sugiere que el virus tiende a ser removido desde el pulmón y a persistir en los tejidos linfoides como fue descrito por Wills y col (2003), quienes detectaron el virus por RT-PCR desde tonsila (2/28) hasta los 251 dpi. Del mismo modo, la escasa detección del antígeno en G2 indicaría que durante las etapas tempranas de la enfermedad (3 y 7 dpi) la excreción viral sería de menor intensidad en comparación con períodos más tardíos, entre los 7 y 28 dpi.

Por otra parte, sólo en un cerdo se detectó antígeno viral en la lámina propia de la mucosa de los cornetes nasales en G1, aunque los cerdos de G3 y G4 presentaron mayor intensidad y constancia de células inmunoteñidas. En estudios previos, la presencia de antígenos fue detectada de forma constante en cerdos inoculados experimentalmente con el aislado chileno del VPPRS entre los 7 y 21 dpi, aunque con leve intensidad (Quezada y col 2005). En otro estudio los antígenos fueron detectados desde las 12 horas post infección, en cerdos de 3 días de edad inoculados con un aislado norteamericano, disminuyendo en intensidad hacia los 21 dpi (Rossow y col 1996). La presencia de escasa reacción inmunohistoquímica en los cerdos de G1 puede ser atribuida a la remoción viral desde este tejido a los 35 dpi; sin embargo, este hallazgo sugiere que los cerdos inoculados pudieron haber excretado virus infeccioso por vía nasal, especialmente entre los 10 y 21 dpi, período en el cual estos animales estuvieron en contacto con los cerdos de G3 y G4, en los cuales se observó la mayor cantidad de células marcadas. De hecho, Christianson y col (1993) aislaron el virus desde secreciones nasales hasta los 9 dpi en cerdas gestantes inoculadas experimentalmente y, por otra parte, Rossow y col (1994) aislaron el virus a los 21 dpi en cerdos de una y cuatro semanas de edad. Del mismo modo, Wills y col $\left(1997^{\circ}\right)$ detectaron el virus desde muestras orofaríngeas entre los 55 y 84 dpi. Estas investigaciones apoyan, de cierta forma, la tesis de que en este estudio una de las posibles vías de transmisión de la enfermedad desde los cerdos de G1 a los grupos de cerdos contacto pudo haber ocurrido por vía nasal.

La viremia fue detectada en los cerdos inoculados entre los 3 y $23 \mathrm{dpi}$, lo cual confirma resultados previos con el aislado chileno (Quezada y col 2005, Ramírez y col 2006) y demuestra que la duración de ésta es más breve en comparación a aislados norteamericanos en los cuales la viremia puede durar entre 4 y 6 semanas (Collins y Rossow 1999). Por otra parte, el hecho de que en los cerdos de G5 se haya demostrado la presencia de antígenos indica que el virus puede transmitirse en ausencia de viremia ya que los cerdos de este grupo estuvieron en contacto con los animales de G1 entre los 24 y 28 dpi, período en cual la viremia ya había cesado; sin embargo, en los grupos contacto sólo se detectó viremia entre los 5 y 12 dpc en los cerdos de G2 y G3, lo cual no concuerda con la presencia de antígenos en los tejidos de 
los cerdos de G4 y G5. Del mismo modo, el virus fue aislado desde tonsila en algunos cerdos de G1 y de todos los grupos contacto y desde pulmón de algunos cerdos de G1, G2, G3 y G5. Estos hallazgos podrían estar dados por la menor sensibilidad del aislamiento viral para detectar bajos niveles de virus circulando en la sangre, especialmente en G4 donde el virus tampoco fue aislado desde pulmón. Por esta razón, sería aconsejable comparar estos resultados con RT-PCR, técnica que ha demostrado ser más sensible que el aislamiento viral en la detección del VPRRS (Spagnuolo-Weaver y col 1998, Wills y col 2003), especialmente en estadios tempranos y tardíos de la infección, cuando hay bajas concentraciones de virus circulantes (Spagnuolo-Weaver y col 1998).

Los resultados obtenidos demuestran que los cerdos inoculados experimentalmente son capaces de transmitir el virus e infectar a los cerdos contacto entre los 3 y 28 dpi y, aunque la carga viral en los cerdos inoculados pareciera ser baja hacia el final de experimento, éstos son capaces de excretar virus infeccioso, transmitirlo incluso en ausencia de viremia y permitir su replicación en los tejidos. En investigaciones similares realizadas previamente se ha demostrado que la principal vía de transmisión ocurre por contacto directo entre animales infectados y susceptibles (Wills y col 1997b , Bierk y col 2001). Aún falta por determinar cuáles serían las principales rutas de excreción, información que resulta fundamental para el mejor entendimiento de los mecanismos de transmisión entre cerdos, especialmente cuando se utilizan animales jóvenes en programas de aclimatización de chanchillas de reemplazo.

Tal como se ha señalado anteriormente, la presencia de un aislado de menor patogenicidad, con manifestaciones clínicas más leves, lesiones menos intensas, menor cantidad de antígeno viral en tejidos y una viremia más corta, tendría un comportamiento epidemiológico diferente a diversos serotipos norteamericanos más patógenos como los encontrados en Estados Unidos y Canadá, por lo que los modelos tendientes a la aclimatización de chanchillas deberían ser ajustados a la realidad nacional. Estudios futuros con el aislado chileno del VPRRS estarán focalizados a determinar las principales rutas y períodos en los cuales el virus es excretado considerando que la duración de la infección y las vías de excreción son un aspecto crítico en la transmisión del VPRRS.

\section{RESUMEN}

El objetivo de este estudio fue determinar la capacidad de transmisión e infección del aislado chileno del virus PRRS a cerdos susceptibles expuestos por contacto directo. Se utilizaron 30 cerdos, divididos en 6 grupos de 5 animales cada uno, uno de los cuales fue inoculado con el virus (G1) y mantenido en la unidad de aislamiento 1 por 35 días, tomándose muestras de sangre a los $0,3,7,11,15,19,23$, 27, 31 y 35 días postinoculación (dpi) para hemogramas y aislamiento viral. Otro grupo (G6) fue usado como control y se mantuvo en la unidad 3. Los grupos restantes (G2, G3, G4, G5) fueron expuestos por contacto directo con G1 entre los 3 a 7,10 a 14,17 a 21 y 24 a 28 dpi, respectivamente, y luego fueron llevados a la unidad 2 permaneciendo en ella por 7 días. Estos animales se muestrearon para hemogramas y aislamiento viral a los 0,5 y 12 días post contacto $(\mathrm{dpc})$. Al sacrificio de G1, G6 (35 dpi) y grupos contacto (12 dpc) se obtuvieron muestras de cornete nasal, tonsila, nódulo linfático submandibular, pulmón y bazo para histopatología e inmunohistoquímica (IHQ) y muestras de tonsila y pulmón para aislamiento. Sólo los cerdos de G1 presentaron fiebre transitoria y no se registraron síntomas respiratorios ni alteraciones en los parámetros hematológicos en todos los grupos. En la necropsia se observó linfoadenopatía en todos los cerdos. Histopatológicamente, todos los animales de G1 tenían neumonía intersticial aunque a través de IHQ se detectaron pocas células inmunoteñidas. En los tejidos linfoides se observaron hiperplasia y necrosis linfoides. En todos los cerdos se detectaron células positivas a IHQ, especialmente en G3 y G4. La viremia fue detectada entre los 3 y 23 dpi en G1 y a los 5 y 12 dpc en G2 y G3; sin embargo, no fue aislado en suero desde G4 y G5. El virus fue aislado desde tonsila en todos los cerdos de G1 y contactos, aunque no fue aislado desde el pulmón de G4. Estos resultados indican que los cerdos inoculados son capaces de transmitir la enfermedad a cerdos susceptibles, incluso en ausencia de viremia durante un período de 28 días.

\section{AGRADECIMIENTOS}

Este trabajo fue financiado por el proyecto FONDECYT (CHILE) $\mathrm{N}^{\circ}$ 1040414. Los autores desean agradecer a las autoridades del Servicio Agrícola y Ganadero por el apoyo al proyecto y al Dr. Fernando Osorio de la Universidad de Nebraska, Lincoln, USA, por el asesoramiento virológico.

\section{REFERENCIAS}

Benfield DA, E Nelson, JE Collins, L Harris, SM Goyal, D Robinson, WT Christianson, RB Morrison, D Gorcyca, D Chladek. 1992. Characterization of swine infertility and respiratory syndrome (SIRS) virus (isolate ATCC VR-2332). J Vet Diagn Invest 4, 127 133.

Bierk, MD, SA Dee, KD Rossow, S Otake, JE Collins, TW Molitor. 2001. Transmission of porcine reproductive and respiratory syndrome virus from persistently infected sows to contact controls. Can J Vet Res 65, 261-266.

Cavanagh, D. 1997. Nidovirales: a new order comprising Coronaviridae and Arteriviridae. Arch Virol 142, 629-633.

Christianson WT, CS Choi, JE Collins, TW Molitor, RB Morrison, HS Joo. 1993. Pathogenesis of porcine reproductive and respiratory syndrome virus infection in mid-gestation sows and fetuses. Can $J$ Vet Res 57, 262-268.

Christopher-Hennings, JC, EA Nelson, JK Nelson, RJ Hines, SL Swenson, HT Hill, JJ Zimmerman, JB Katz, MJ Yaeger, CC Chase, DA Benfield. 1995. Detection of porcine reproductive and respiratory syndrome virus in boar semen by PCR. J Clin Microbiol 33, 1730-1734.

Chung, HK, Ch Choi, J Kim, Ch Chae. 2002. Detection and differentiation of North American and European genotypes of porcine reproductive and respiratory syndrome virus in formalinfixed, paraffin-embedded tissues by multiplex reverse transcription-nested polymerase chain reaction. J Vet Diagn Invest $14,56-60$.

Collins JE, DA Benfield, WT Christianson, L Harris, JC Hennings, DP Shaw, SM Goyal, S McCullough, RB Morrison, HS Joo. 1992. Isolation of swine infertility and respiratory syndrome virus (isolate ATCC VR-2332) in North America and experimental 
reproduction of the disease in gnotobiotic pigs. J Vet Diagn Invest 4, 117-126.

Collins J, K Rossow. 1999. Detecting the porcine reproductive and respiratory syndrome virus infected pigs. Proceedings of the American Association of Swine Practitioners, USA, Pp 313-317.

Cuartero L, S Dee, J Deen, A Ruiz, C Pijoan. 2002. Association between clinical signs and high serum titers of porcine reproductive and respiratory syndrome virus (PRRSV) in nursery pigs under field conditions. J Swine Health Prod 10, 119-122.

Dee S. 1997. An overview of production systems designed to prepare naive replacement gilts for impending PRRSV challenge: A global perspective. J Swine Health Prod 5, 231-239.

Drew TW. 2000. A review of evidence for immunosuppression due to porcine reproductive and respiratory syndrome virus. Vet Res 31 , 27-39.

Faaberg KS, S Yuan, B Schmidt, M Murtaugh. 1999. Porcine reproductive and respiratory syndrome virus: detection of viral recombination. Proceeding of American Association of Swine Practitioners, USA, Pp 403-407.

Friendship, RM, SC Henry. 1992. Cardiovascular system, haematology and clinical chemistry. En: Leman AD, Straw BE, Mengeling WL, D'Allaire S, Taylor DJ (eds). Diseases of Swine. (7th ed). Iowa State University Press, Ames, USA, Pp 3-11.

Halbur, PG, PS Paul, ML Frey, J Landgraf, K Eernisse, XJ Meng, JJ Andrews, MA Lum, JA Rathje. 1996a. Comparison of the antigen distribution of two US porcine reproductive and respiratory syndrome virus isolates with that of the Lelystad virus. Vet Pathol 33, 159-170.

Halbur, PG, PS Paul, XJ Meng, MA Lum, JJ Andrews, JA Rathje. $1996^{\mathrm{b}}$. Comparative pathogenicity of nine US porcine reproductive and respiratory syndrome (PRRSV) isolates in a five-week-old cesaream-derived, calostrum-deprived pig model. J Vet Diag Invest 8, 11-20.

Halbur, PG, FJ Pallarés, JA Rathje, R Evans, WA Hagemoser, PS Paul, XJ Meng. 2002. Effects of different US isolates of porcine reproductive and respiratory syndrome virus (VPRRS) on blood and bone marrow parameters of experimentally infected pigs. Vet Rec 151, 344-348.

Kim, HS, J Kwang, IJ Yoon, HS Joo, ML Frey. 1993. Enhanced replication of porcine reproductive and respiratory syndrome (PRRS) virus in a homogeneus subpopulation of MA-104 cell line. Arch Virol 133, 477-483.

Labarque, G, S Van Gucht, H Nauwynck, K Van Reeth, M Pensaert. 2003. Apoptosis in the lungs of pigs infected with porcine reproductive and respiratory syndrome virus and associations with the production of apoptogenic cytokines. Vet Res 34, 249-260.

Murtaugh, MP, KS Faaberg, J Laber, M Elam, V Kapur. 1998. Genetic variation in the PRRS virus. Adv Exp Med Biol 440, 787-794.

Nelson, EA, J Christopher-Hennings, T Drew, G Wensvoort, JE Collins, DA Benfield. 1993. Differentiation of US and European isolates of porcine reproductive and respiratory syndrome virus by monoclonal antibodies. J Clin Microbiol 31, 3184-3189.

Nielsen, J, A Bøtner. 1997. Hematological and immunological parameters of $41 / 2$ month old pigs infected with PRRS virus. Vet Microbiol 55, 289-294.

Otake, S, SA Dee, KD Rossow, HS Joo, J Deen, TW Molitor, C Pijoan. $2002^{a}$. Transmission of porcine reproductive and respiratory syndrome virus by needles. Vet Rec 150, 114-115.

Otake, S, SA Dee, KD Rossow, J Deen, HS Joo, TW Molitor, C Pijoan. $2002^{\mathrm{b}}$. Transmission of porcine reproductive and respiratory syndrome virus by fomites (boot and coveralls). J Swine Health Prod 10, 59-65.

Otake, S, SA Dee, KD Rossow, RD Moon, C Pijoan. 2002 . Mechanical transmission of porcine reproductive and respiratory syndrome virus by mosquitoes, Aedes vexans (Meigen). Can J Vet Res 66, 191-195.
Otake, S, SA Dee, L Jacobson, M Torremorell, C Pijoan. 2002 ${ }^{\mathrm{d}}$. Evaluation of aerosol transmission of porcine reproductive and respiratory syndrome virus under controlled field conditions. Vet $\operatorname{Rec} 150,804-808$.

Otake, S, SA Dee, KD Rossow, RD Moon, C Trincado, C Pijoan. 2003. Transmission of porcine reproductive and respiratory syndrome virus by houseflies (Musca domestica). Vet Rec 152, 73-76.

Pinilla J, M Rojas, L Cuevas. 2006. PRRSV eradication in Chile: A country-wide approach. Proceedings of the American Association Of Swine Veterinarians, USA, Pp 409-416.

Quezada M, F Varas, A Ruiz, A Islas, N Díaz, C. Lecocq. 2005. Detección inmunohistoquímica del antígeno del virus del síndrome respiratorio y reproductivo (vPRRS) en cerdos inoculados. Arch Med Vet 36, 183-194.

Ramírez E, A Ruiz, A Islas, C Lecocq, L Carrasco, M Quezada. 2006. Características hematológicas y patológicas de cerdos inoculados experimentalmente con el aislado chileno del virus Síndrome Respiratorio y Reproductivo Porcino (vPRRS). Arch Med Vet 38 (2), 151-159.

Rossow KD, EM Bautista, SM Goyal, TW Molitor, MP Murtaugh, RB Morrison, DA Benfield, JE Collins. 1994. Experimental porcine reproductive and respiratory syndrome virus infection in one-, four-, and 10-week-old pigs. J Vet Diag Invest 6, 3-12.

Rossow, KD, JE Collins, SM Goyal, EA Nelson, J ChristopherHennings, DA Benfield. 1995. Pathogenesis of porcine reproductive and respiratory syndrome virus infection in gnotobiotic pigs. Vet Pathol 32, 361-373.

Rossow KD, DA Benfield, SM Goyal, EA Nelson, J ChristopherHennings, JE Collins. 1996. Chronological immunohistochemical detection and localization of porcine reproductive and respiratory syndrome virus in gnotobiotic pigs. Vet Pathol 33, 551-556.

Ruiz A, L Cuevas, J Naranjo. 2003. Chile: Program to eradicate PRRS virus. En: Zimmerman J, Yoon KJ. (eds) 2003 PRRS Compendium. National Pork Board, Iowa, USA, Pp 221-222.

Schalm, OW, NC Jain, EJ Carroll. 1975. Material and methods for the study of the blood, including brief comments on factors to be considered in interpretation. En: Schalm OW, Jain NC, Carroll EJ (eds). Veterinary Hematology. Lea \& Febiger, Philadelphia, USA, Pp 15-81.

Spagnuolo-Weaver M, IW Walker, F McNeilly, V Calvert, D Graham, K Burns, BM Adair, GM Allan. 1998. The reverse transcription polymerase chain reaction for the diagnosis of porcine reproductive and respiratory syndrome: comparison with virus isolation and serology. Vet Microbiol 62, 207-215.

Suárez, P. 2000. Ultrastructural pathogenesis of the PRRS virus. Vet Res 31, 47-55.

Sur JH, AR Doster, FA Osorio. 1998. Apoptosis induced in vivo during acute infection by porcine reproductive and respiratory syndrome virus. Vet Pathol 35, 506-514.

Swenson SL, HT Hill, JJ Zimmerman, LE Evans, JG Landgraf, RW Wills, TP Sanderson, MJ Mc Ginley, AK Brevik, DK Ciszewsky, ML Frey. 1994. Excretion of porcine reproductive and respiratory syndrome virus in semen after experimentally induced infection in boars. J Am Vet Med Assoc 204, 1943-1948.

Thorn CE. 2000. Normal hematology of pig. En: Feldman BE, Zink1 JG, Jain NC (eds). Schalm's Vet Hematol. Philadelphia, USA. Pp 1089-1095.

Wensvoort G, C Terpstra, JM Pol, EA Ter Laak, M Bloemraad, EP de Kluyver, C Kragten, L Van Buiten, A Den Besten, F Wagenaar. 1991. Mystery swine disease in The Netherlands: the isolation of Lelystad virus. Vet $Q 13,121-130$.

Wills RW, JJ Zimmerman, KJ Yoon, SL Swenson, MJ McGinley, HT Hill, KB Platt, J Christopher-Hennings, EA Nelson. 1997a. Porcine reproductive and respiratory syndrome virus: a persistent infection. Vet Microbiol 55, 231-240. 
Wills RW, JJ Zimmerman, SL Swenson, KJ Yoon, HT Hill, DS Bundy, MJ McGinley 1997b. Transmission of VPRRS by direct, close, or indirect contact. $J$ Swine Health and Prod 5, 213-218.

Wills RW, JJ Zimmerman, LW Swenson, LJ Hoffman, MJ McGinley, HT Hill, KB Platt. $1997^{\circ}$. Porcine reproductive and respiratory syndrome virus: Routes of excretion. Vet Microbiol 57, 69-81.

Wills RW, AR Doster, JA Galeota, JH Sur, FA Osorio. 2003. Duration of infection and proportion of pigs persistently infected with porcine reproductive and respiratory syndrome virus. $J$ Clin Microbiol 4, 58-62.

Yoon KJ, HS Joo, WT Christianson, RB Morrison, GD Dial. 1993. Persistent and contact infection in nursery pigs inoculated experimentally infected with of porcine reproductive and respiratory syndrome (PRRS) virus. J Swine Health Prod 1, $5-8$. 